\title{
FLUXO DE NUTRIENTES PELA PRECIPITAÇÃO PLUVIOMÉTRICA EM DOIS TRECHOS DE FLORESTA OMBRÓFILA DENSA EM GUARAQUEÇABA, PARANÁ
}

\author{
Maurício Bergamini Scheer ${ }^{1}$ \\ ${ }^{1}$ Eng. Florestal, M.Sc., Doutorando em Engenharia Forestal UFPR, SANEPAR, Curitiba, PR, Brasil - mauriciobs@ sanepar.com.br
}

Recebido para publicação: 16/04/2008 - Aceito para publicação: 08/06/2008

\begin{abstract}
Resumo
Este trabalho teve o objetivo de avaliar os fluxos de $\mathrm{K}, \mathrm{Ca}, \mathrm{Mg}$ e $\mathrm{Na}$ através da precipitação no exterior e no interior de dois trechos de Floresta Ombrófila Densa (capoeira: estágio inicial/intermediário de sucessão secundária de floresta aluvial e floresta secundária submontana), na Reserva Natural Salto Morato, em Guaraqueçaba, Paraná. A capoeira e a floresta secundária apresentaram valores de interceptação da água da chuva em torno de $14 \%$, sendo baixos comparados com outros da literatura. As estimativas para a deposição do Na pela precipitação foram elevadas se comparadas às de outros trabalhos, alcançando uma média anual de $83 \mathrm{~kg} / \mathrm{ha}$ na precipitação externa e de $96 \mathrm{~kg} / \mathrm{ha}$ na precipitação no interior da capoeira. Entre os macronutrientes analisados, para o mesmo processo, foram estimadas deposições anuais de $52 \mathrm{~kg} / \mathrm{ha} \mathrm{de} \mathrm{K,} 5 \mathrm{~kg} / \mathrm{ha}$ de Ca e 2,9 kg/ha de $\mathrm{Mg}$, ocorrendo os maiores aportes durante o período mais quente e chuvoso. Os valores para a floresta secundária foram um pouco menores, principalmente para o K. Somando com dados da contribuição da serapilheira no mesmo período, disponíveis para a capoeira, a precipitação interna representou respectivamente, $65 \%, 5 \%$ e $15 \%$ da deposição total desses nutrientes no solo, indicando a importância desse processo para a restauração e/ou manutenção dos elementos minerais dentro dos ecossistemas estudados.

Palavras-chave: Ciclagem de nutrientes; interceptação do dossel; precipitação interna; sucessão secundária; macronutrientes.
\end{abstract}

\begin{abstract}
Nutrient flow in rainfall and throughfall in two stretches in an Atlantic Rain Forest in southern Brazil. The returns of $\mathrm{K}, \mathrm{Ca}, \mathrm{Mg}$ and $\mathrm{Na}$ through rainfall and throughfall (in an early to midde successional alluvial forest and in a secondary lowland forest) were estimated in an Atlantic Rain Forest in Southern Brazil. The two forests showed interception rainfall values around 14\%, considered low comparing to other studies. The Na values were very high, reaching in average $83 \mathrm{~kg}$ $\mathrm{ha}^{-1} \mathrm{y}^{-1}$ in rainfall and $96 \mathrm{~kg} \mathrm{ha}^{-1} \mathrm{y}^{-1}$ in throughfall in the early to midde secondary forest. The annual nutrient returns in througfall were: of $52 \mathrm{~kg} \mathrm{ha}^{-1}$ of $\mathrm{K}, 5 \mathrm{~kg} \mathrm{ha}^{-1}$ of Ca and $2.9 \mathrm{~kg} \mathrm{ha}^{-1}$ of $\mathrm{Mg}$, with major contributions during the rainy season. The secondary forest presented lower values, mainly for $\mathrm{K}$. Additioning to available litterfall data in early to midde secondary forest, througfall contributed to $65 \%$ of $\mathrm{K}, 5 \%$ of $\mathrm{Ca}$ and $15 \%$ of $\mathrm{Mg}$ returned to the soil pointing out the relevance of this process to the restoration and/or maintenance of these elements into the studied ecosystems.

Keywords: Nutrient cycling; canopy interception; secondary succession; throughfall, macronutrients.
\end{abstract}

\section{INTRODUÇÃO}

Apesar da intemperização de minerais primários ser considerada a maior fonte para a formação do estoque de nutrientes em ecossistemas terrestres, em muitos ambientes tropicais, com solos mais antigos, onde remanescem poucos minerais não intemperizados na profundidade das raízes, o fluxo de elementos químicos via atmosfera torna-se a maior fonte de nutrientes (KELLMAN et al., 1982; SCHRUMPF et al., 2006). Esses nutrientes encontram-se sob a forma de gases ou de aerossóis secos, incluindo emissões de sais marinhos, poeiras terrestres, gases poluentes e emissões vulcânicas, ou integrando partículas finas como pó ou pólen, sendo arrastados pela precipitação, dissolvidos ou em 
suspensão (LIKENS et al., 1977). Anderson; Spencer, citados por Britez (1994), indicam uma faixa entre 7 e $11 \%$ da deposição de elementos minerais via atmosfera (apenas deposição úmida), condicionando a ciclagem mineral a uma estreita dependência com o ciclo hidrológico. A precipitação interna (água que atravessa a vegetação e chega ao solo) contém alta concentração da maioria dos nutrientes. Além de arrastar as partículas da atmosfera e aquelas depositadas sobre a vegetação, a precipitação também lixivia órgãos vegetais vivos e mortos, exsudados das plantas, excrementos e cadáveres de animais, menos a porção retida (troca de íons) ou adsorvida e absorvida durante a trajetória (CLAYTON, 1972; CORNU et al., 1998, SCHRUMPF et al., 2006).

A água que atravessa a vegetação tem fundamental importância no retorno imediato de nutrientes ao solo, pois geralmente acrescenta mais da metade do $\mathrm{K}$ em circulação, mais que um terço da quantidade de $\mathrm{P}$ e $\mathrm{Mg}$, embora acrescente muito menos que um terço de $\mathrm{N}$ e Ca (VITOUSEK; SANFORD JR., 1986). Isso significa que, para alguns elementos, o processo da lavagem da vegetação pela água da chuva pode ser mais efetivo que a própria deposição da serapilheira na ciclagem biogeoquímica de ecossistemas florestais (ARCOVA; CICCO, 1987). O estudo desses fluxos pode trazer informações relevantes sobre as interações solo-planta-atmosfera e a ciclagem de nutrientes (MARQUES; RANGER, 1998). Segundo Hansen, citado por Marques e Ranger (1998), as maiores concentrações de elementos na água ocorrem no início do evento de precipitação. Apesar de concentrações elevadas na água que escoa pelos troncos, o volume por esse processo é extremamente pequeno quando comparado à água que atravessa o dossel, geralmente menor que 1\% da precipitação total (EDWARDS, 1982; ARCOVA; CICCO, 1987; ARCOVA et al., 2003; SCHRUMPF et al., 2006). A água que atravessa a vegetação recebe um novo aporte de nutrientes ao atravessar a camada serapilheira, devido ao contato com os nutrientes liberados pelo processo de decomposição. Nesse compartimento do ecossistema, a maior parte dos nutrientes presentes na solução é absorvida pelas raízes das plantas. A parte da solução que penetra no solo e é exportada para o lençol freático, e consequentemente para a bacia de drenagem, geralmente contém teores mais baixos de elementos (SANTOS, 1989).

As entradas atmosféricas de nutrientes tornam-se ainda mais importantes em ambientes sucessionais (prisseres e subseres). Esses fluxos têm grande contribuição para um incremento da resiliência, que é fundamental para a regeneração de áreas muito degradadas. Nas florestas em regeneração, a entrada de nutrientes pela precipitação pode exceder a saída por lixiviação, desde que a biomassa e suas reservas de nutrientes estejam aumentando (VITOUSEK; REINERS, 1975; JORDAN, 1982). Portanto, o processo de imobilização de elementos químicos na vegetação em regeneração à montante nas bacias hidrográficas pode contribuir para diminuir o excesso de nutrientes e de sedimentos à jusante, restaurando as características originais dos ecossistemas, principalmente os aquáticos. Segundo Grubb (1995), poucos estudos têm avaliado a ciclagem de nutrientes através da água da chuva que atravessa o dossel da floresta e da que escorre pelos troncos das árvores. No Brasil são escassas as pesquisas que quantificaram fluxos de nutrientes através da precipitação pluviométrica (entre outros, COUTINHO, 1979; ARCOVA; CICCO, 1987; LIMA, 1986; DOMINGOS et al., 2000).

Portanto, como parte de um projeto de pesquisa que visa contribuir para o entendimento de processos sucessionais em trechos de Floresta Ombrófila Densa Atlântica, visando seu manejo e restauração, o presente estudo da ciclagem de nutrientes têm os seguintes objetivos: (I) avaliar quais são as diferenças entre os volumes das precipitações pluviométricas externa (lavagem atmosférica) e interna (água que atravessa o dossel de uma capoeira e de uma floresta secundária avançada); (II) avaliar quais dos elementos analisados ( $\mathrm{K}, \mathrm{Ca}, \mathrm{Mg}$ e $\mathrm{Na}$ ) apresentam maiores teores e quantidades depositadas; (III) avaliar quais as interações dos elementos na água ao atravessar a vegetação; e (IV) avaliar em qual época do ano são disponibilizadas as maiores quantidades desses elementos para a biota.

\section{MATERIAIS E MÉTODOS}

\section{Áreas de estudo}

As áreas de estudo estão situadas na Reserva Natural Salto Morato (RNSM), Guaraqueçaba, litoral norte do Paraná, no domínio da Floresta Ombrófila Densa (VELOSO et al., 1991), nas coordenadas $25^{\circ} 10^{\prime} 45^{\prime \prime}$ de latitude Sul e $48^{\circ} 17^{\prime} 48^{\prime \prime}$ de longitude Oeste (Figura 1). A região em questão está situada na bacia do rio Morato, uma sub-bacia do rio Guaraqueçaba, pertencente à bacia hidrográfica das Laranjeiras. As linhas de drenagem são jovens e ainda apresentam elevado gradiente de velocidade. Existe um grande potencial de erosão, considerando a proximidade de suas cabeceiras com o oceano ou 
nível de base, apesar de que, na tomada das planícies aluviais, os rios desenvolvem feições do tipo canais anastomosados (FBPN, 1995). estudos:

Apresenta-se a seguir a descrição das duas formações vegetacionais em que se desenvolveram os

1) Estágio inicial/intermediário de sucessão secundária de floresta aluvial: a aproximadamente $20 \mathrm{~m}$ s.n.m. e com 9 anos de regeneração natural, localiza-se a aproximadamente $500 \mathrm{~m}$ de uma floresta secundária submontana avançada, fonte de propágulos (Figura 1). Foram encontradas 36 espécies lenhosas, apresentando uma densidade de 2820 indivíduos/ha e uma área basal de $22,2 \mathrm{~m}^{2} / \mathrm{ha}$, adotando perímetro à altura do peito $(\mathrm{PAP})>10 \mathrm{~cm}$ (SCHEER, 2006). Nessa fisionomia predominam indivíduos arbóreos com altura média de oito metros, ocorrendo Myrsine coriacea (Sw.) R. Br. Ex Roem. \& Schult., Senna multijuga (Rich.) H. S. Irwin \& Barneby, Cecropia pachystachya Trécul, Tibouchina pulchra Cogn., Psidium guajava L. (exótica) e remanescentes de Citharexylum myrianthum Cham., frequentemente formando um dossel contínuo. Dentre as espécies arbustivas, são importantes Piper aduncum L., Boehmeria caudata Sw. e Solanum fastigiatum Willd. As principais espécies herbáceas ocorrentes na área são: Vernonia scorpioides (Lam.) Pears., Manettia congesta (Vell.) K. Schum., Rubus rosifolius Stokes var. rosifolius e Clidemia hirta D. Don, entre outras. Nessa fisionomia ocorrem indivíduos jovens de espécies arbóreas que provavelmente irão dominar a comunidade no próximo estágio sucessional, como Hyeronima alchorneoides M. Allem., Vochysia bifalcata Warm., Matayba sp., Cordia sylvestris Sw., Euterpe edulis Mart. e Hirtella hebeclada Moric. ex DC., entre outras. Segundo Mocochinski et al. (2003), foi constatada a predominância de Neossolos Flúvicos (típico e gleico) e de Cambissolos Hísticos, ambos distróficos, derivados de sedimentos recentes (inconsolidados - Cenozóico) originados da Serra do Morato, composta por granitos e migmatitos (FBPN, 1995; MINEROPAR, 2001). 2) Estágio avançado da sucessão secundária, formação submontana: a aproximadamente $500 \mathrm{~m}$ da capoeira de estudo (Figura 1), essa área, com provavelmente mais de 50 anos de regeneração natural, situa-se em uma encosta com exposição sul, com aproximadamente $30 \%$ de declividade e com a altitude de $80 \mathrm{~m}$ s.n.m. É comum a presença de indivíduos remanescentes de Ficus spp., atingindo mais de $20 \mathrm{~m}$ de altura, além de indivíduos de outras espécies, como Alchornea triplinervia (Spreng.) Müll. Arg., Sloanea guianensis (Aubl.) Benth., Eugenia multicostata D. Legrand, Vochysia bifalcata, Hyeronima alchorneoides Allemão. Nos estratos inferiores, são comuns indivíduos de Euterpe edulis, Bathysa meridionalis e Psychotria nuda. Os solos, segundo Embrapa (2006), são classificados como Cambissolos e Neossolos Litólicos, ambos distróficos.

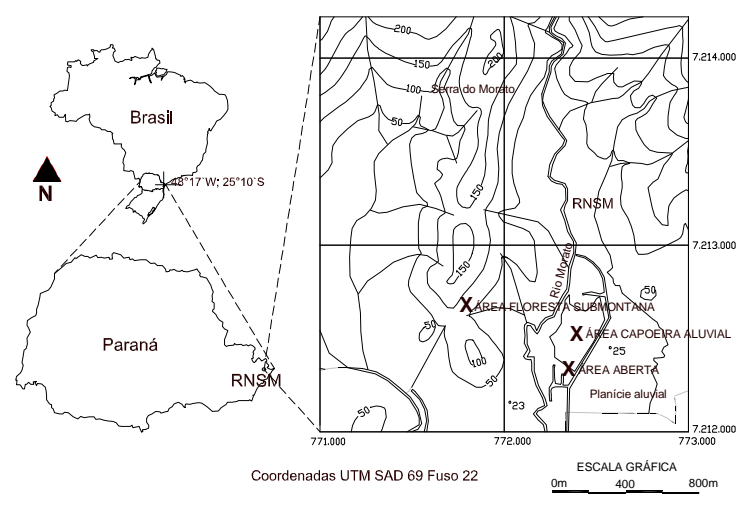

Figura 1. Mapa de localização geográfica das áreas de estudo (Reserva Natural Salto Morato) no município de Guaraqueçaba (PR).

Figure 1. Geographic location of the study areas at Salto Morato Natural Preserve (RNSM), Guaraqueçaba, state of Paraná, Brazil. 
Essa formação foi escolhida devido à dificuldade de se encontrar uma formação aluvial em estágio mais avançado (maior degradação das áreas de planície), para serem feitas comparações das precipitações no interior das florestas com diferentes idades de regeneração.

\section{Clima}

O clima na região, segundo Köppen, é Cfa, ou subtropical. No entanto, Maack (1968) preferiu considerar o litoral como de clima tropical Af (acrescentando a letra t, por representar transição), justificando apresentar as mesmas condições fisiográficas do litoral paulista entre Santos e Cananéia. Detalhes podem ser observados no diagrama climático (Figura 2) construído segundo Walter (1986).

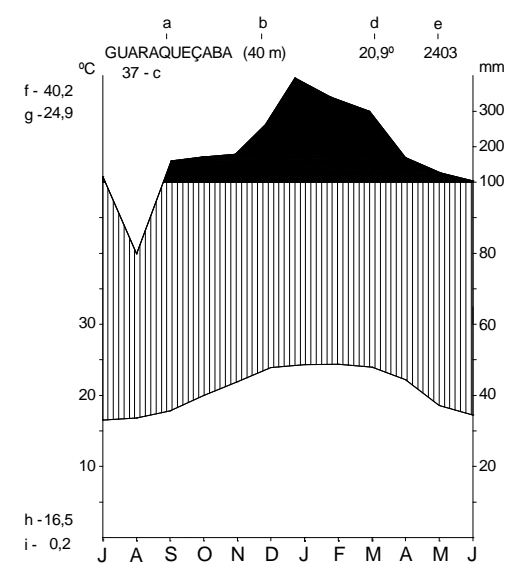

NOTA: traço inferior: curva de temperatura média; traço superior: curva de precipitação pluviométrica; hachura vertical: estação relativamente úmida; hachura escura: estação superúmida, precipitação média mensal > 100 mm (escala reduzida a 1/10); a: estação meteorológica; b: altitude; c: $\mathrm{n}^{\mathrm{o}}$ de anos de observação; d: temperatura média anual; e: precipitação média anual; f: temperatura máxima absoluta; g: temperatura média diária do mês mais quente; h: temperatura média diária do mês mais frio; i: temperatura mínima absoluta.

Figura 2. Diagrama climático da região de Guaraqueçaba (SCHEER, 2006). Dados da estação meteorológica do IAPAR; período entre 1978 e 2005.

Figure 2. Climate diagram of the Guaraqueçaba region (SCHEER, 2006). Data during the period from 1978 to 2005 (IAPAR 2006).

\section{Precipitação pluviométrica externa e interna}

Para a amostragem da água da chuva que atravessa a vegetação na capoeira e na floresta secundária (precipitação interna), foram confeccionados 15 coletores de precipitação (pluviômetros) para cada situação, constituídos basicamente de funis de polietileno (diâmetro de 12,5 cm; $123 \mathrm{~cm}^{2}$ de área de recepção) com peneira na base, conectados a um recipiente plástico (5 litros) através de uma mangueira fina.

Replicatas de sítios nesse tipo de estudo não são comuns devido à baixa relação custo benefício, ainda mais que o objetivo desses trabalhos é estudar as áreas pesquisadas e não ter a pretensão de extrapolar para todas as formações florestais semelhantes. Hurlbert, citado por Dezzeo e Chacón (2006), afirma que é comum e aceitável que experimentos de campo em ecologia sejam realizados dessa forma.

Em uma área aberta, para representar a precipitação que atravessa a atmosfera antes de passar pela vegetação (precipitação externa), foram instalados 6 coletores. As coletas foram realizadas a cada duas semanas (durante o período entre 23/09/2001 e 21/09/2003), medindo-se todos os volumes com uma proveta, agrupando a água dos coletores em um galão de 20 litros e tirando uma alíquota de cada tipo de precipitação. As amostras foram filtradas (em filtro qualitativo) e congeladas, para posteriormente serem compostas, na proporção medida, amostras mensais (28 dias) para a determinação de $\mathrm{K}, \mathrm{Ca}, \mathrm{Mg}$ e $\mathrm{Na}$.

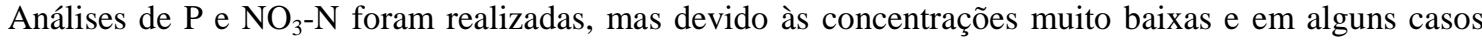


fora do limite de detecção, optou-se por suspender tais análises. Dezzeo; Chacón (2006), entre outros estudos, também encontraram valores baixos desses nutrientes na precipitação pluviométrica.

Após as coletas, os coletores eram lavados com a água restante do galão e, posteriormente com um pouco de água deionizada, para remoção do excesso aderido na parede dos frascos. Também foram colocados cristais de timol através de um conta-gotas, para minimizar a atividade microbiana, procedimento também utilizado em outros trabalhos, conforme Meguro et al. (1979b), Santos (1989) e Britez (1994).

A interceptação da água pela vegetação foi calculada através da subtração da precipitação interna da precipitação externa.

Os fluxos dos elementos foram calculados multiplicando-se os teores pelos volumes de água coletados em cada período, extrapolando-se a área de captação dos coletores para hectare.

Scheer (2006) realizou uma revisão de informações de diversos trabalhos a respeito de considerações sobre amostragem, estocagem e preparo de amostras de água de chuva. Entre diversos autores, cita Ostapczuk (1997), que afirma que ainda não existe método seguro que determine os valores exatos dos elementos químicos na precipitação. No entanto, para a determinação dos ânions $\mathrm{SO}_{4}, \mathrm{NO}_{3}$, $\mathrm{Cl}$, e dos cátions $\mathrm{Na}, \mathrm{K}, \mathrm{Mg}$ e Ca, afirma que somente a filtragem e armazenagem a $4{ }^{\circ} \mathrm{C}$ são suficientes para conservar as amostras por várias semanas. Para as análises de elementos-traço (geralmente poluentes) é necessária a digestão ácida. Quando a amostra é filtrada, é também necessária a digestão do filtro com o material retido.

Alguns meses de coleta foram acompanhados com um pluviômetro de medidas diárias no mesmo local, resultando em valores muito próximos aos dos pluviômetros medidos a cada duas semanas (precipitação externa). Considerando que a peneira e a mangueira fina impedem maiores perdas da água coletada por quebra de capilaridade, foi desprezada a possível evaporação das amostras.

\section{Análises químicas}

Todas as análises químicas foram efetuadas no Laboratório de Biogeoquímica e Nutrição Mineral de Plantas (LABINP) do Departamento de Solos e Engenharia Agrícola da Universidade Federal do Paraná (UFPR). Para a determinação dos teores de K, Na, Ca e Mg nas amostras de água, foi utilizado o espectrofotômetro de absorção atômica 2380 Perkin-Elmer (K e Na por emissão).

\section{Análises estatísticas}

Para se verificarem diferenças estatísticas nos volumes de precipitação pluviométrica nos dois tipos florestais, foi realizado o teste de $t$ de Student $(\mathrm{p}<0,05)$. Após a verificação de normalidade, homogeneidade de variâncias e aditividade. Para análise dos comportamentos dos teores dos elementos e dos volumes de precipitação ao longo dos meses (dados não paramétricos), foram calculados os coeficientes de correlação de Spearman $\left(\mathrm{r}_{\mathrm{s}}\right)$.

\section{RESULTADOS E DISCUSSÕES}

\section{Precipitação pluviométrica externa, interceptação pela vegetação e precipitação interna}

Na figura 3 estão apresentadas as médias mensais de precipitação externa e das duas situações de precipitação interna na RNSM. A precipitação externa no primeiro ano do experimento (período entre $24 / 09 / 2001$ e 22/09/02) foi de $2681 \mathrm{~mm}$, e no segundo ano (22/09/02 a 21/09/03) foi de $2671 \mathrm{~mm}$. O período mais chuvoso ocorreu nos meses de maiores temperaturas, entre dezembro e abril, culminando em março. O período menos chuvoso foi entre junho e outubro (Figura 3).

Conforme a tabela 1, a interceptação da água da chuva foi similar nos dois tipos de vegetação, embora alguns valores tenham sido maiores na capoeira (16\%) do que na floresta secundária (13\%), porém sem diferenças estatisticamente significativas (teste de $t, n=15$ ). Os valores de interceptação pelas copas das árvores estão um pouco abaixo dos encontrados na literatura, geralmente entre 18 e $36 \%$. O valor mais próximo ao do presente trabalho $(16,6 \%)$ foi encontrado por Leopoldo e Conte (1985), em um trecho de Cerradão, em São Paulo. Arcova et al. (2003), em trabalho em Floresta Atlântica Submontana secundária, em São Paulo, encontraram valores em torno de 19\% de interceptação, sendo $26 \%$ no período menos chuvoso e $16 \%$ no período mais chuvoso. Britez (1994) detectou um valor médio de $22 \%$ de interceptação para um trecho de formação pioneira com influência marinha (restinga baixa) e de $30 \%$ para 
uma restinga alta, em Paranaguá, no Paraná. Domingos et al. (1995), em estudo de florestas perturbadas pela poluição atmosférica em Cubatão, São Paulo, encontraram valores de interceptação de 3\% e 36\%, respectivamente, para floresta mais afetada e menos afetada pela poluição. Schubart et al. (1984) registraram $26 \%$ de interceptação para floresta amazônica de terra firme, enquanto que Cornu et al. (1998) encontraram 8\% de interceptação. Meguro et al. (1979b) e Santos (1989), em trabalhos em Floresta Estacional Semidecidual secundária, registraram, respectivamente, valores médios de $30 \%$ e $28 \%$ de interceptação pelas copas das árvores.

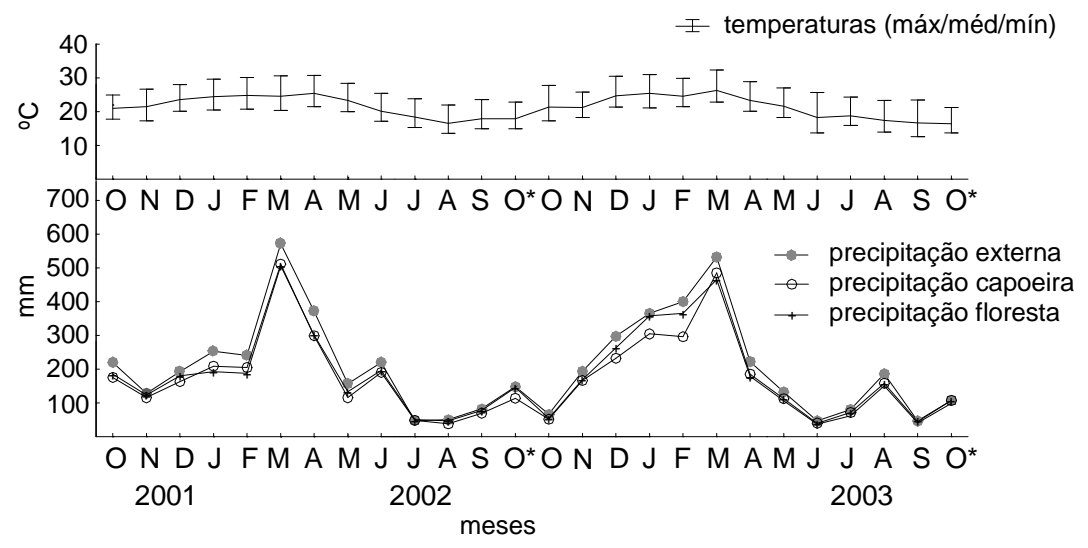

Figura 3. Precipitação pluviométrica externa e precipitações internas (dossel da capoeira e floresta secundária) durante o período de estudo na RNSM, no município de Guaraqueçaba (PR). Os dados de temperatura foram fornecidos pelo SIMEPAR, na estação do IAPAR, em Guaraqueçaba.

Figure 3. Seasonal patterns of rainfall and througfall $(\mathrm{mm})$ in the study areas, at RNSM, Guaraqueçaba, Paraná, Brazil. Mean monthly values of minimum, mean and maximum temperatures $\left({ }^{\circ} \mathrm{C}\right)$, were assigned by SIMEPAR, IAPAR's Guaraqueçaba station, at $40 \mathrm{~m}$ above sea level at $26 \mathrm{~km}$ far from the study area.

Tabela 1. Teores médios de elementos químicos durante os 2 anos do experimento nas três situações de precipitação pluviométrica estudadas, em $(\mu \mathrm{g} / \mathrm{mL})$.

Table 1. Annual average chemical element concentrations $(\mu \mathrm{g} / \mathrm{mL})$ in rainfall and througfall $(\mathrm{mm})$ in the study areas, at RNSM, Guaraqueçaba, Paraná, Brazil.

\begin{tabular}{lcccccc}
\hline & Precip. (mm) & Intercep. \% & K & Ca & Mg & Na \\
\hline Externa & 2676 & - & 0,25 & 0,04 & 0,19 & 3,12 \\
Capoeira & 2251 & 16 & 2,30 & 0,22 & 0,13 & 4,26 \\
Floresta & 2335 & 13 & 1,23 & 0,18 & 0,09 & 3,93 \\
\hline
\end{tabular}

Os baixos valores de interceptação encontrados no presente estudo para a capoeira (16\%) podem ser justificados pela pequena área basal, por não apresentar um dossel totalmente contínuo e por não haver a presença de dois ou mais estratos arbóreos. Por essa mesma razão, a menor interceptação (13\%) da floresta secundária avançada é difícil de explicar. Provavelmente está relacionada com o microclima mais úmido no interior da floresta em função dos vários estratos que a compõem, ocorrendo menor perda da água retida por evaporação (condensação), mantendo umidade para um gotejamento posterior, o que resulta em um maior volume de água alcançando o solo. A floresta secundária também pode ter sido sujeita a um volume de precipitação externa um pouco diferente devido à distância entre os pluviômetros (aproximadamente $600 \mathrm{~m}$ ) e ainda por ter sofrido influência da exposição sul e da declividade da encosta, que pode favorecer a retenção de neblina (menor insolação), aumentando o volume precipitado. A capoeira, por receber relativamente mais insolação direta e por apresentar um dossel menos denso, fica mais sujeita à evaporação (sem um retorno significativo por condensação) por ação da maior insolação e velocidade dos ventos.

Os seis coletores de precipitação externa foram considerados suficientes para a amostragem, pois os coeficientes de variação foram em média menores do que $3 \%$ e os erros padrões menores que $1 \%$. 
Pequenos erros podem também estar relacionados à proximidade dos coletores, que foram instalados com aproximadamente $2 \mathrm{~m}$ de distância. Allen et al. (1968) estimaram erros entre 0,4 e 1,9\%, utilizando 5 coletores de $25 \mathrm{~cm}$ de diâmetro. Os 15 coletores para cada situação de precipitação interna também podem ser considerados satisfatórios, apresentando coeficientes de variação em média menores do que $30 \%$ e erros padrões menores que $10 \%$. Schrumpf et al. (2006) detectaram erros entre 10 e $20 \%$ utilizando-se entre 8 e 10 coletores de $11,5 \mathrm{~cm}$ de diâmetro para cada sítio estudado.

\section{Teores de elementos minerais na precipitação pluviométrica}

\section{Precipitação externa}

Na tabela 1 estão os teores médios dos elementos depositados pela precipitação externa e pela interna nos dois sítios estudados. Na figura 4 estão as variações sazonais dos teores relativas ao período amostral (26 períodos de 28 dias). Pode-se observar a grande variação encontrada nos valores médios dos teores dos elementos analisados na precipitação externa. As variações dos valores mensais $(\mathrm{em} \mu \mathrm{g} / \mathrm{mL})$ foram: 1,4 a 6,7 para o $\mathrm{Na}$; 0,1 a 0,68 para o K; 0,01 a 0,68 para o $\mathrm{Mg}$ e 0,01 a 0,15 para o Ca. Segundo Silva Filho et al. (1986) e Arcova et al. (1993), as grandes variações nos teores da água da chuva ao longo dos meses devem-se à quantidade, intensidade e distribuição das precipitações, às alterações na trajetória de massas de ar e à contribuição de diferentes fontes injetoras de íons na atmosfera. Brown et al. (1985), estudando as entradas atmosféricas em Floresta Atlântica no Rio de Janeiro, através de análises de erros de duplicatas, verificaram que a amplitude dos dados encontrada foi produto da variabilidade na amostragem e não das técnicas analíticas. No presente trabalho, tal variação foi constatada nos teores médios de $\mathrm{Mg}$, que foram superiores no segundo ano amostrado (de 0,11 para $0,26 \mu \mathrm{g} / \mathrm{mL}$ ), enquanto que os teores de $\mathrm{Na}$ foram inferiores (de 3,96 para 2,27 $\mu \mathrm{g} / \mathrm{mL}$ ).

Os teores mensais de $\mathrm{K}$ e $\mathrm{Mg}$ apresentaram correlação negativa com os volumes mensais da precipitação pluviométrica $\left(\mathrm{r}_{\mathrm{s}}=-0,56 ; \mathrm{p}<0,005 ; \mathrm{n}=26\right)$. Segundo Allen et al. (1968), Meguro et al. (1979) e Arcova et al. (1993), nos períodos com menores precipitações, as partículas em suspensão acumuladas na atmosfera são arrastadas por um pequeno volume de água, resultando em teores mais elevados de elementos minerais.

Comparando com os valores encontrados por Britez (1994), em restinga próxima à área de estudo, a média encontrada para o $\mathrm{K}$ foi de $0,3 \mu \mathrm{g} / \mathrm{mL}$, um pouco maior que no presente estudo, para o $\mathrm{Mg}$ foi 0,5 (2 vezes maior que no presente estudo) e para o $\mathrm{Ca}, 0,31$ ( 7 vezes maior que no presente estudo). Arcova e Cicco (1987), em Floresta Atlântica em São Paulo, encontraram teores um pouco maiores para o $\mathrm{K}(0,35 \mu \mathrm{g} / \mathrm{mL})$.

\section{Precipitação interna}

A amplitude dos teores estimados para a precipitação interna na capoeira, em $\mu \mathrm{g} / \mathrm{mL}$, foram de 2,3 a 9,6 para $\mathrm{Na}$, de 0,75 a 8,0 para $\mathrm{K}$, de 0,09 a 0,98 para $\mathrm{Ca}$ e de 0,02 a 0,45 para $\mathrm{Mg}$ (valores médios na Tabela 1). Para a precipitação interna na floresta secundária, os valores variaram de 1,74 a 8,66 para $\mathrm{Na}$; de 0,28 a 4,02 para K; de 0,02 a 0,56 para Ca e de 0,02 a 0,27 para Mg (Tabela 1). As variabilidades espaciais e temporais das amostras são aceitáveis e comuns neste tipo de estudo e pouco prejudicam as estimativas ao longo do ano (CORNU et al., 1998).

Nota-se que nas duas situações de precipitação interna, os teores de Ca são superiores aos de $\mathrm{Mg}$, ao contrário da precipitação antes de arrastar os nutrientes da vegetação. Os teores médios dos elementos analisados, principalmente de $\mathrm{Ke} \mathrm{Ca}$, foram maiores na capoeira do que na floresta secundária avançada.

Foram encontradas fortes correlações negativas dos teores de $\mathrm{K}$, $\mathrm{Ca}$ e $\mathrm{Mg}$ com o volume da precipitação interna na capoeira, sendo $r_{s}=-0,824$ para o $\mathrm{K}, r_{s}=-0,782$ para o Ca e $r_{s}=-0,670$ para o $\mathrm{Mg}$ ( $\mathrm{p}<0,001, \mathrm{n}=26$ ). Para a precipitação na floresta secundária, os coeficientes foram um pouco mais fracos, sendo $\mathrm{r}_{\mathrm{s}}=-0,782$ para o $\mathrm{K},-0,512$ para o $\mathrm{Mg},-0,413$ para o Ca e também $-0,410$ para o $\mathrm{Na}(\mathrm{p}<$ $0,05, \mathrm{n}=26$ ). Dezzeo; Chacón (2006) obtiveram coeficientes similares para $\mathrm{K}, \mathrm{Ca}$ e $\mathrm{Mg}$. Isso provavelmente deve-se ao acúmulo de partículas em suspensão na atmosfera quando há um intervalo maior sem chuva. Provavelmente, uma chuva subsequente de pequena intensidade, comum na época menos chuvosa, é suficiente para arrastar tais partículas, resultando em teores maiores na época menos chuvosa. Já as chuvas de grande intensidade, comuns na época chuvosa, diluem a água durante cada intervalo de coleta, diminuindo os teores dos elementos.

$\mathrm{Na}$ figura 4, nota-se que o comportamento do $\mathrm{Na}$ nas duas situações de precipitação interna é muito similar ao da precipitação externa, a qual representa a maior parte da contribuição. 
Teores

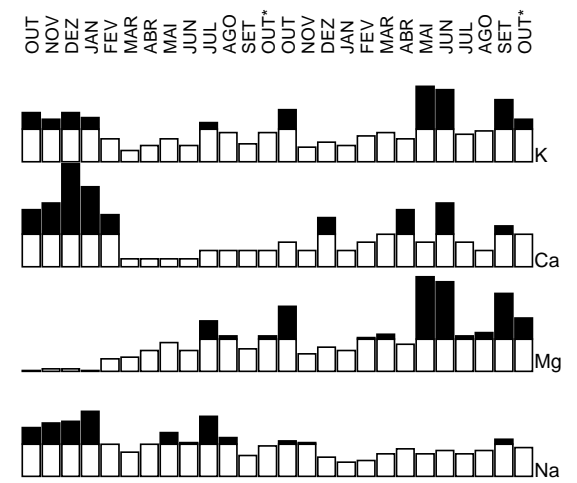

Quantidades

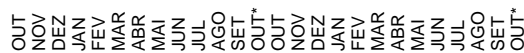
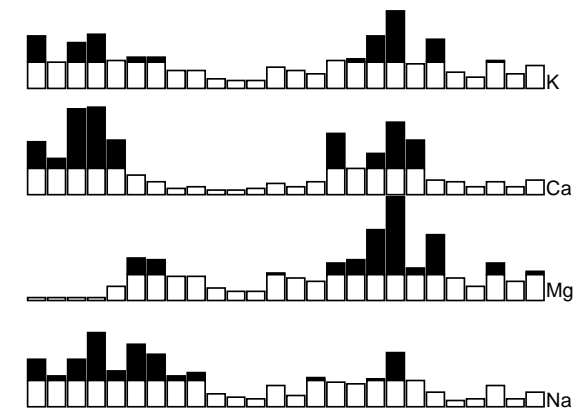

Precipitação Interna (capoeira)

Teores

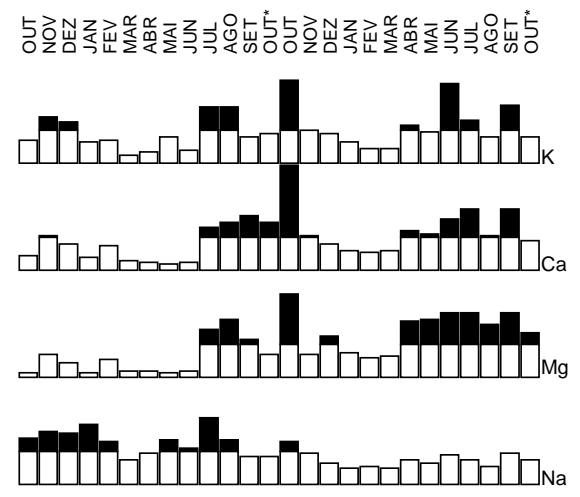

Quantidades
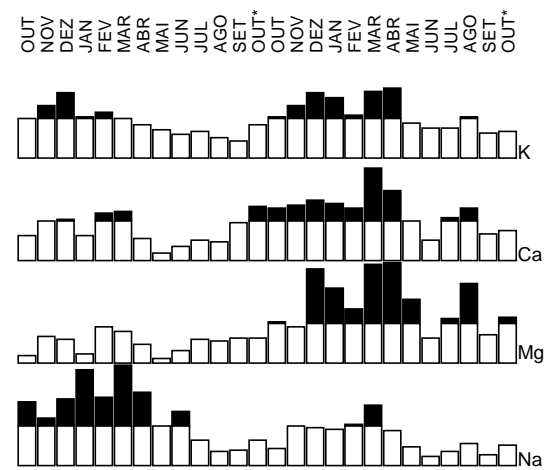

Precipitação Interna (floresta)

Teores

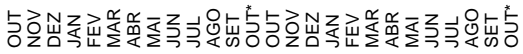
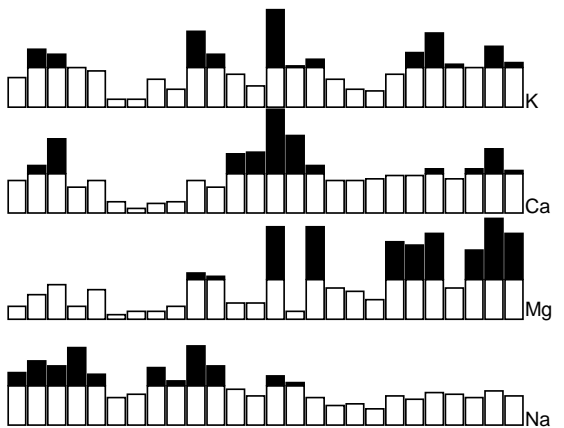

Quantidades

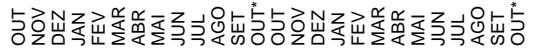
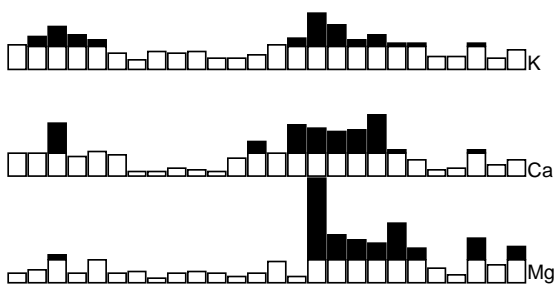

प117

Figura 4. Variação sazonal dos teores e das quantidades de $\mathrm{K}, \mathrm{Ca}, \mathrm{Mg}$ e Na relativa ao período amostrado (26 períodos de 28 dias). As barras escuras são valores acima da média (ver tabelas 1 e 2).

Figure 4. Seasonal patterns of element concentrations and flows in rainfall and througfall (relative contributions) in the study areas, at RNSM, Guaraqueçaba, Paraná, Brazil. Dark shaded bars represent values above the means.

\section{Considerações sobre as variações dos teores}

Com o objetivo de estimar a variação dos teores de elementos em cada coleta entre coletores, para os dois sítios de precipitação interna, os pluviômetros mais próximos foram agrupados de três em 
três, considerando a proporção de cada volume medido. Através das cinco repetições de análises de água na capoeira, foram estimados os seguintes valores dos erros padrões: $11 \%$ para $\mathrm{Ca}, 15 \%$ para o $\mathrm{Mg}$ e $\mathrm{K} \mathrm{e}$ $7 \%$ para o Na. Os respectivos coeficientes de variação foram: 24, 33, 33 e 16\%. Para as cinco repetições na água da chuva que atravessa a floresta secundária, os erros padrões foram: $26 \%$ para o Ca, $29 \%$ para o $\mathrm{Mg}, 19 \%$ para o K e $3 \%$ para o Na. Os coeficientes de variação (em \%) foram, respectivamente: 57,66 , 42 e 6. Tais valores indicam uma menor variabilidade para os teores de $\mathrm{Ca}, \mathrm{K}$ e $\mathrm{Mg}$ no interior da capoeira em relação à floresta secundária, o que poderia ser explicado pela maior heterogeneidade na composição do dossel na floresta secundária. Corroborando o presente trabalho, Dezzeo ;Chacón (2006) obtiveram nas concentrações mensais de $\mathrm{K}, \mathrm{Ca}$ e $\mathrm{Mg}$ coeficientes de variação entre 70 e 100\%, utilizando-se de nove coletores em cada uma das 3 formações florestais estudadas, indicando uma ampla variabilidade espacial no interior dessas florestas.

\section{Fluxos de elementos minerais na precipitação pluviométrica}

Os fluxos médios de elementos pela precipitação externa seguem a seguinte ordem de grandeza: $\mathrm{Na}>\mathrm{K}>\mathrm{Mg}>\mathrm{Ca}$ (Tabela 2). De acordo com os valores registrados pela literatura presentes na tabela 3, os valores podem ser considerados altos para $\mathrm{Na}$ (principalmente no $1^{\circ}$ ano do estudo $=106,1 \mathrm{~kg} / \mathrm{ha} / \mathrm{ano}$ ), medianos para $\mathrm{K}$ e baixos para $\mathrm{Ca}$ e $\mathrm{Mg}$.

Tabela 2. Médias pluviométricas de precipitação externa e interna na capoeira e na floresta secundária avançada e quantidades (fluxos) anuais de elementos depositados (em kg/ha).

Table 2. Annual average element fluxes (kg.ha-1) in rainfall and througfall (mm) in the study areas, at RNSM, Guaraqueçaba, Paraná, Brazil.

\begin{tabular}{lcccccc}
\hline & Precip. (mm) & Intercep. \% & K & Ca & Mg & Na \\
\hline Externa* & 2676 & - & 6,7 & 1,2 & 5,0 & 83,4 \\
Capoeira & 2251 & 16 & 51,7 & 5,0 & 2,9 & 95,9 \\
Floresta & 2335 & 13 & 28,7 & 4,2 & 2,1 & 91,8 \\
\hline
\end{tabular}

*Relações $\mathrm{Ca} / \mathrm{Mg}=0,24 ; \mathrm{Na} / \mathrm{Mg}=16,7 ; \mathrm{Na} / \mathrm{K}=12,4 ; \mathrm{Na} / \mathrm{Ca}=70$

O período de maiores aportes dos elementos minerais foi entre o meio da primavera e o final do verão (Figura 4), época mais quente e chuvosa. Essa via parece ter uma grande contribuição no fornecimento de nutrientes para o aumento da produtividade primária nesse período. Foram encontradas correlações significativas positivas entre as quantidades de elementos depositados e as precipitações externa e interna nos dois sítios analisados. Para a precipitação externa: $r_{s}=0,811$ para o Na, $r_{s}=0,747$ para o K, $\mathrm{r}_{\mathrm{s}}=0,672$ para o Ca e $\mathrm{r}_{\mathrm{s}}=0,493$ para o $\mathrm{Mg}(\mathrm{p}<0,02, \mathrm{n}=26)$. Para a precipitação na capoeira, os coeficientes foram: 0,827, 0,616 e 0,441, respectivamente, para o Na, o K e o $\mathrm{Ca}(\mathrm{p}<0,03, \mathrm{n}=26)$. Para a precipitação na floresta secundária, os coeficientes foram um pouco mais fracos: $r_{s}=0,789$ para $o$ $\mathrm{Na}, \mathrm{r}_{\mathrm{s}}=0,541$ para o Ca e $\mathrm{r}_{\mathrm{s}}=0,504$ para o $\mathrm{K}(\mathrm{p}<0,02, \mathrm{n}=26)$. Isso indica que o volume de chuva rege as quantidades de elementos depositados no solo da floresta, mas não os teores, corroborando Cornu et al. (1998), entre outros autores.

Foi nota da a importância da água da chuva no retorno dos nutrientes para o solo, principalmente a contribuição do K, que no segundo ano do experimento contribuiu com aproximadamente $58 \mathrm{~kg} / \mathrm{ha}$ na lavagem do "dossel" da capoeira, comportamento também observado por Meguro et al. (1979b), Santos (1989), Britez (1994) e SCHRUMPF et al. (2006), entre outros autores. A chuva que atravessou a capoeira arrastou aproximadamente o dobro da quantidade de $\mathrm{K}$ lixiviada em comparação com a floresta secundária (Tabelas 2 e 3). Marques; Ranger (1998), em estudo de uma cronossequência de povoamentos de Pseudotsuga menziesii, na França, sugeriram que as quantidades mais altas de K lixiviadas das copas do povoamento mais jovem estudado (20 anos) se devem à maior taxa de crescimento, promovendo uma forte absorção foliar de $\mathrm{NH}_{4}{ }^{+} \mathrm{N}$, que resulta na liberação do íon $\mathrm{K}$.

Ao atravessar a capoeira, a água da precipitação foi enriquecida em sete vezes para o K $(51,7$ $\mathrm{kg} / \mathrm{ha} / \mathrm{ano})$, quatro vezes para o $\mathrm{Ca}(5 \mathrm{~kg} / \mathrm{ha} / \mathrm{ano})$ e 1,1 vezes para o $\mathrm{Na}(95,9 \mathrm{~kg} / \mathrm{ha} / \mathrm{ano})$. Já o $\mathrm{Mg}$ diminuiu em $60 \%$ em relação à precipitação externa $(2,9 \mathrm{~kg} / \mathrm{ha} / \mathrm{ano})$. Na floresta secundária, o enriquecimento em $\mathrm{K}$ foi cerca de 4 vezes, e da mesma ordem que na capoeira para os demais elementos (Tabela 3). Em floresta submontana na Nova Guiné, Edwards (1982) encontrou um aumento na precipitação interna de nove vezes para o $\mathrm{K}$ e $\mathrm{Mg}$, de cinco vezes para o Ca e $\mathrm{P}$ e de 4,6 vezes para o $\mathrm{N}$. 
Schrumpf et al. (2006), em floresta montana na Tanzânia, encontraram um aumento para a precipitação interna de cinco vezes para o $\mathrm{K}, 2,4$ vezes para o $\mathrm{Mg}, 1,8$ para o $\mathrm{Na}$ e 1,6 para o $\mathrm{Ca}$ (Tabela 3). Cornu et al. (1998), em floresta amazônica em Manaus, encontraram um aumento de 12 vezes para o $\mathrm{Na}$, atribuindo-o à lavagem da deposição seca e principalmente de exsudados da biota. Tais variabilidades nos resultados indicam a importância desses estudos para se obterem parâmetros sobre os diversos ecossistemas existentes, considerando suas diferentes posições geográficas e graus de interferência antrópica, entre outros fatores.

Tabela 3. Estimativas anuais dos fluxos de elementos através da precipitação externa e interna em diferentes trechos de florestas tropicais (em kg/ha/ano) (FODAl - aluvial); (FODSub submontana); (FODM - Montana); (FODAmTF - amazônica de terra firme).

Table 3. Annual average element fluxes $\left(\mathrm{kg} \cdot \mathrm{ha}^{-1}\right)$ in rainfall and througfall $(\mathrm{mm})$ in some tropical and subtropical forests.

\begin{tabular}{|c|c|c|c|c|c|c|c|c|c|c|}
\hline \multirow{2}{*}{$\begin{array}{l}\text { Tipo } \\
\text { vegetacional }\end{array}$} & \multirow{2}{*}{ Local } & \multicolumn{4}{|c|}{ Precip. externa } & \multicolumn{4}{|c|}{ Precip. interna } & \multirow{2}{*}{ Referência } \\
\hline & & $\mathbf{K}$ & $\mathbf{C a}$ & Mg & $\mathrm{Na}$ & $\mathbf{K}$ & $\mathbf{C a}$ & Mg & $\mathbf{N a}$ & \\
\hline \multicolumn{11}{|c|}{ Brasil } \\
\hline Restinga & PR & 3,5 & 4,8 & 7,4 & & 49,9 & 11,4 & 14,6 & & Britez (1994) \\
\hline Restinga & PR & 3,5 & 4,8 & 7,4 & & 44,8 & 12,1 & 14,2 & & Britez (1994) \\
\hline FODAl & PR & 6,7 & 1,2 & 5,0 & 83,4 & 51,7 & 5,0 & 2,9 & 95,9 & Este estudo \\
\hline FODSub & PR & 6,7 & 1,2 & 5,0 & 83,4 & 28,7 & 4,2 & 2,1 & 91,8 & Este estudo \\
\hline FODSub & RJ & 5,3 & 7,0 & 6,2 & 26,0 & & & & & Silva Filho et al. (1986) \\
\hline FODSub & SP & 6,0 & 19,0 & 3,0 & & 18,0 & 41,0 & 6,0 & & Domingos et al. \\
\hline FODSub & SP & 6,0 & 13,0 & 4,0 & & 35,0 & 35,0 & 7,0 & & Domingos et al. \\
\hline FODM & SP & 5,4 & 2,9 & 1,7 & 11,8 & 79,9 & 11,5 & 7,2 & 20,7 & Arcova; Cicco (1987) \\
\hline FOD AmTF & $\mathrm{AM}$ & 2,4 & & & & 22,1 & 1,0 & 7,8 & 8,4 & Franken et al. (1985) \\
\hline FOD AmTF & $\mathrm{AM}$ & 2,1 & & & & 22,1 & & & & Schubart et al.(1984) \\
\hline FOD AmTF & $\mathrm{AM}$ & & & & 15,8 & & & & 184, & Cornu et al. (1998) \\
\hline FESDec & SP & 2,4 & & & & 126 & & & & Meguro et al. (1979b) \\
\hline FESDec & PR & 8,2 & 10,4 & 3,6 & 3,8 & 88,4 & 17,7 & 9,7 & & Santos (1989) \\
\hline Cerrado & SP & 2,6 & 5,6 & 0,9 & 3,5 & & & & & Coutinho et al. (1979) \\
\hline Cerradão & SP & & & & & 77,6 & 23,5 & 12,3 & 25,5 & Lima (1986) \\
\hline \multicolumn{11}{|c|}{ Florestas tropicais em outras partes do mundo } \\
\hline Trop. Montane & Honduras & 2,0 & 16,0 & 18,0 & 4,0 & & & & & Kellman et al. (1982) \\
\hline Trop. Montane & Tanzânia & 7,5 & 2,3 & 0,9 & 6,2 & 35,0 & 3,5 & 2,0 & 11,0 & Schrumpf et al. (2006) \\
\hline Trop. Montane & Nova Guiné & 7,3 & 19,0 & 10,9 & & 71,1 & 19,0 & 10,9 & & Edwards (1982) \\
\hline Trop. Montane & Venezuela & 2,2 & 0,8 & 1,31 & & 36,4 & 5,7 & 4,8 & & Dezzeo; Chacón (2006) \\
\hline Trop. Montane & Venezuela & 2,2 & 0,8 & 1,31 & & 37,5 & 4,1 & 5,0 & & Dezzeo; Chacón (2006) \\
\hline Trop. Montane & Venezuela & 2,2 & 0,8 & 1,31 & & 32,3 & 7,1 & 4,2 & & Dezzeo; Chacón (2006) \\
\hline Upper Montane & Colombia & 7,9 & 10,1 & 3,2 & 24,1 & 95,2 & 27,1 & 10,7 & 26,4 & Veneklaas (1990) \\
\hline Upper Montane & Venezuela & 2,6 & 5,6 & 5,2 & 3,3 & 69,7 & 6,9 & 3,3 & 4,4 & Grimm; Fassbender (1981) \\
\hline Upper Montane & Costa Rica & 5,9 & 5,2 & 0,8 & 2,3 & 54,7 & 12,8 & 4,1 & 2,3 & Hölscher et al. (2003) \\
\hline Upper Montane & Costa Rica & 5,9 & 5,2 & 0,8 & 2,3 & 41,1 & 12,4 & 3,4 & 4,1 & Hölscher et al. (2003) \\
\hline Upper Montane & Costa Rica & 5,8 & 4 & 0,7 & 3,0 & 61,8 & 14,8 & 5,4 & 3,2 & Hölscher et al. (2003) \\
\hline
\end{tabular}

Entre outros autores, Arcova; Cicco (1987), em Floresta Atlântica em São Paulo, observaram uma tendência indicando que $\mathrm{K}, \mathrm{Ca}$ e $\mathrm{Mg}$ são elementos fortemente arrastados da vegetação pela água das chuvas. Edwards (1982) e Cornu et al. (1998), entre outros autores, sugeriram que o aumento de nutrientes, principalmente do $\mathrm{Ca}$, na precipitação interna está relacionado à lavagem de exsudados da vegetação e à decomposição de ramos e galhos ainda nas copas das árvores. Já o $\mathrm{P}$ e o Na na água da chuva (Tabelas 1, 2 e 3), geralmente são provenientes primeiramente pela lavagem de aerossóis da atmosfera. Porém, em alguns casos, como no trabalho de Cornu et al. (1998), a lavagem de exsudados das plantas pode ter maior contribuição. No entanto, no presente estudo houve uma redução dos teores e quantidades de $\mathrm{Mg}$ ao atravessar as copas das árvores, indicando que grande parte desse elemento provavelmente tenha ficado retida na vegetação. Steinhardt, citado por Schrumpf et al. (2006), e Grimm e 
Fassbender (1981) também encontraram uma retenção do Mg, ambos em florestas montanas, na Venezuela. Franken et al. (1985), em floresta de terra firme na Amazônia, detectaram um mesmo padrão, mas para $\mathrm{NH}_{4}$, sugerindo a rápida volatilização desse elemento na forma de $\mathrm{N}_{2} \mathrm{O}$ ou $\mathrm{N}$ ou alta absorção foliar pela microflora. Já Schrumpf et al. (2006) registraram o mesmo padrão para $\mathrm{NO}_{3}$, em floresta montana no Monte Kilimanjaro, na Tanzânia, corroborando outras florestas citadas no seu trabalho. Dezzeo; Chacón (2006) também encontraram perdas de $\mathrm{N}$ na precipitação interna.

No presente trabalho, foi encontrada uma relação $\mathrm{Na} / \mathrm{K}$ igual a 12,4 , provavelmente indicando uma forte influência do $\mathrm{Na}$ proveniente do mar. Os elevados teores de $\mathrm{Na}$ (e também de $\mathrm{Mg}$ e $\mathrm{Cl}$ ) geralmente estão associados à proximidade do mar, sendo suas concentrações influenciadas pelas massas de ar oceânicas (CLAYTON, 1972; SILVA-FILHO et al., 1986; ARCOVA et al., 1985; 1993). Allen et al. (1968) citaram relação $\mathrm{Na} / \mathrm{K}$ mais próxima de 28 , como indicadora de origem marinha, mas para comparações devem-se levar em consideração, além da distância do sítio, os movimentos das massas de ar pelo relevo. Segundo Clayton (1972), as relações $\mathrm{Na} / \mathrm{K}$ e $\mathrm{Na} / \mathrm{Ca}$ tendem a diminuir com a continentalidade, ao passo que a relação $\mathrm{Na} / \mathrm{Mg}$ tende a aumentar, pois os níveis de $\mathrm{Mg}$ parecem diminuir mais rápido que o $\mathrm{Na}$ à medida que aumenta a distância do mar. No presente trabalho, as relações $\mathrm{Na} / \mathrm{Ca} \mathrm{e}$ $\mathrm{Na} / \mathrm{Mg}$ foram muito altas, respectivamente, 70 e 16,7.

Gore (1968) cita a relação $\mathrm{Ca} / \mathrm{Mg}$ utilizada por Chapman para identificar o ponto no qual os depósitos em turfeiras mudam de predominantemente continentais para predominantemente atmosféricos. Mattson et al., citados por Gore (1968), propuseram como critério o valor dessa relação igual a 0,196, similar ao da água do mar. Vários autores afirmaram que essa razão geralmente aumenta com a distância do mar, mas que também pode estar relacionada a eventos antropogênicos recentes. No presente trabalho, essa relação foi estimada em 0,24 , indicando uma forte influência oceânica. Com as quantidades de elementos na chuva estimadas por Arcova; Cicco (1987), em Floresta Ombrófila Densa Montana, em São Paulo, foi obtida uma relação $\mathrm{Ca} / \mathrm{Mg}$ igual a 1,71. Para o trabalho de Santos (1989), em Floresta Estacional Decidual no Paraná, a relação $\mathrm{Ca} / \mathrm{Mg}$ foi de 2,88, e para um Cerrado, em São Paulo, o valor estimado foi de 6,22 (COUTINHO et al., 1979). Esses resultados indicam um aumento da relação nos sítios mais distantes do mar.

Em trabalho realizado no mesmo período e local (conforme Scheer, 2006), 27,9 kg de K, 94,7 kg de $\mathrm{Ca}$ e 16,8 $\mathrm{kg}$ de $\mathrm{Mg}$ foram depositados anualmente via queda de serapilheira. Dos 79,5 kg/ha/ano da deposição de K estimada através da soma dos aportes no solo via precipitação interna e via queda de serapilheira, 65\% foram provenientes do primeiro processo. Dos 99,6 kg/ha/ano da deposição de Ca, apenas $5 \%$ foram provenientes da chuva nessa fisionomia. Dos $19,7 \mathrm{~kg} / \mathrm{ha} / \mathrm{ano}$ da deposição de $\mathrm{Mg}$, apenas 15\% foram provenientes da precipitação interna. Dezzeo; Chacón (2006), para três tipos florestais na Venezuela, encontraram valores de contribuição da precipitação interna em torno de 80,15 e $31 \%$, respectivamente, para $\mathrm{K}, \mathrm{Ca}$ e $\mathrm{Mg}$. É importante ressaltar que os nutrientes da água da chuva geralmente estão prontamente disponíveis, enquanto que os da serapilheira são liberados gradualmente pela decomposição. Essa via torna-se ainda mais importante quando as outras fontes de nutrientes são escassas.

\section{CONCLUSÕES}

A seqüência decrescente dos elementos depositados pelos diversos tipos de precipitação foi: $\mathrm{Na}$ $>\mathrm{K}>\mathrm{Ca}>\mathrm{Mg}$. As estimativas para a deposição do Na pela precipitação foram elevadas quando comparadas com outros trabalhos, e em parte devem-se à proximidade do mar (aprox. $5 \mathrm{~km}$ da baía das Laranjeiras). Os maiores aportes de elementos durante o período mais quente e chuvoso do ano parecem ter grande contribuição para o fornecimento e ciclagem de nutrientes prontamente disponíveis para a produtividade primária, para o desenvolvimento das fases reprodutivas da vegetação e também para o estabelecimento de novos indivíduos nas fases iniciais da sucessão.

$\mathrm{O} \mathrm{Mg}$ na precipitação interna apresentou uma interação oposta aos outros elementos, pois parte ficou retida na vegetação.

$\mathrm{O}$ macronutriente que apresentou maiores deposições foi o $\mathrm{K}$, principalmente na capoeira (provavelmente relacionada à maior taxa de crescimento com absorção foliar do $\mathrm{NH}_{4} \mathrm{e}$ à liberação do $\mathrm{K}$ ). Foi notada a importância da precipitação interna no retorno dos nutrientes para o solo, principalmente a contribuição do K. Foi estimado que $65 \%$ do fluxo desse elemento para o solo (serapilheira + precipitação 
interna) foram através desse processo na capoeira. Para o $\mathrm{Ca}$ e o $\mathrm{Mg}$, a precipitação interna representou respectivamente 5 e $15 \%$ do fluxo para cada elemento.

Tais resultados indicam que a água de precipitação pluviométrica, tanto como veículo de arraste de elementos da atmosfera como da deposição seca e de exsudados da biota, é uma importante via para a restauração e/ou manutenção dos elementos minerais dentro dos ecossistemas estudados.

\section{AGRADECIMENTOS}

O autor agradece ao Programa de Pós-Graduação em Engenharia Florestal da Universidade Federal do Paraná, ao PIBIC/CNPq e à CAPES, pela concessão das bolsas de estudo, ao IAPAR e ao SIMEPAR, pelas informações meteorológicas cedidas, aos professores Celina Wisniewski e Renato Marques, pela orientação, e ao pesquisador Ricardo Miranda de Britez, pelo apoio prestado. Agradeço também à equipe do "Projeto Sucessão", do qual este trabalho faz parte; em especial a Gustavo Gatti, Alan Mocochinski, André Cavassani, Francisco Putini e Alexandre Lorenzetto, que também participaram da execução dessa pesquisa.

Este trabalho foi financiado pela Fundação O Boticário de Proteção à Natureza e apoiado pela Sociedade Fritz Müller de Ciências Naturais.

\section{REFERÊNCIAS}

ALLEN, S. E.; CARLISE, A.; WHITE, E. J.; EVANS, C. C. The plant nutrient content of rainwater. Journal of Ecology, Oxford, v. 9, p. 497-504, 1968.

ARCOVA, F. C. S; CICCO, V. Fluxo de nutrientes através da precipitação interna e escoamento pelo tronco em floresta natural secundária no Parque Estadual da Serra do Mar, Núcleo Cunha, SP. Boletim Técnico do Instituto Florestal, São Paulo, v. 41, n. 1, p. 37-58, março, 1987.

ARCOVA, F. C. S; CICCO, V.; LIMA, W. P. Balanço dos nutrientes $\mathrm{Ca}, \mathrm{Mg}, \mathrm{Na}, \mathrm{K}$ e $\mathrm{NO}_{3}$ em bacia hidrográfica experimental com vegetação natural do Parque Estadual da Serra do Mar, Núcleo Cunha, SP. Boletim Téc,nico do Instituto Florestal, São Paulo, v. 31, p. 61-67, 1985.

ARCOVA, F. C. S; CICCO, V.; ROCHA, P. A. B. Precipitação efetiva e interceptação das chuvas por floresta de mata atlântica em uma microbacia experimental em Cunha, São Paulo. Revista Árvore, Viçosa-MG, v. 27, n. 2, p. 257-262, 2003.

ARCOVA, F. C. S; CICCO, V.; SHIMOMICHI, P. Y. Qualidade da água e dinâmica dos nutrientes em bacia hidrográfica recoberta por floresta de mata atlântica. Revista do Instituto Florestal, São Paulo, v. 5, n. 1, 1-20, 1993.

BRITEZ, R. M. Ciclagem de nutrientes minerais em duas florestas da planície litorânea da Ilha do Mel, Paranaguá, PR.. 240 f. Dissertação (Mestrado em Agronomia) - Setor de Ciências Agrárias, Universidade Federal do Paraná, Curitiba, 1994.

BROWN, S.; LUGO, A. The storage and production of organic matter in tropical forest and their role in the global carbon cycle. Biotropica, Washington, DC, v. 14, n. 3, p. 161-187, 1982.

CLAYTON, J. L. Salt spry and mineral cycling in two California coastal ecosystems. Ecology, Durham, v. 53, p. 74-81, 1972.

CORNU, S.; AMBROSE, J. P.; LUCAS, Y; DESJARDINS, T. Origin and behavior of dissolved chlrorine and sodium in Brazilian Rainforest. Water Research, London, v. 32, n. 4, p. 1151-1161, 1998.

COUTINHO, L. M. Aspectos ecológicos do fogo no cerrado. III - A precipitação atmosférica de nutrientes minerais. Revista Brasileira de Botânica, São Paulo, v. 2, p. 97-101, 1979.

DEZZEO, N.; CHACÓN, N. Nutrient fluxes in incident rainfall, throughfall, and stemflow in adjacent primary and secondary forests of the Gran Sabana, southern Venezuela. Forest Ecology and Management, Amsterdan, v. 234, p. 218-226, 2006. 
DOMINGOS, M.; POGGIANI, F.; STRUFFALDI-DE VUONO, Y.; LOPES, M. I. M. S. Precipitação pluvial e fluxo de nutrientes na floresta da Reserva Biológica de Paranapiacaba, sujeita aos poluentes atmosféricos de Cubatão, SP. Revista Brasileira de Botânica, São Paulo, v. 18, n. 1, p. 119-131, 1995.

DOMINGOS, M. L.; SILVEIRA, M. I. M.; STRUFFALDI-DE VUONO, Y. Nutrient cycling disturbance in Atlantic Forest sites affected by air pollution coming from the industrial complex of Cubatão, Southeast Brazil. Revista Brasileira de Botânica, São Paulo, v. 23, n. 1, p. 77-85, 2000.

EDWARDS, P. J. Studies of mineral cycling in a montane rain forest in New Guinea. V. Rates of cycling in througfall and litter fall. Journal of Ecology, Oxford, v. 70, p. 807-827, 1982.

EMPRESA BRASILEIRA DE PESQUISA EM AGROPECUÁRIA. Sistema brasileiro de classificação de solos. Rio de Janeiro: EMBRAPA/Centro Nacional de Pesquisas em Solos, 2006.

FUNDAÇÃO O BOTICÁRIO DE PROTEÇÃO DA NATUREZA. Reserva Natural Salto Morato Plano de manejo. São José dos Pinhais, 1995.

FRANKEN, W; LEOPOLDO, P. R.; BERGAMIN, H. Nutrient flow through natural waters in "terra firme" forest in central Amazon. Turrialba, San Jose, v. 35, n. 4, p. 383-393, 1985.

GORE, A. J. P. The supply of six elements by rain to an upland peat area. Journal of Ecology, Oxford, v. 56, p. 483-495, 1968.

GRIMM, U.; FASSBENDER, H. W. Ciclos bioquímicos en un ecosistema forestal de los Andes Occidentales de Venezuela. III. Ciclo hidrológico y translocación de elementos químicos con el agua. Turrialba, San Jose,, v. 31, n. 2, p. 89-99, 1981.

GRUBB, P. J. Mineral nutrition and soil fertility in tropical rain forests. In: LUGO, A. E.; LOWE, C. (Ed.). Tropical Forests: management and ecology. New York: Springer, 1995, p. 308-330. (Ecological Studies, v. 112).

HÖLSCHER, D.; KÖHLER, L.; LEUSCHNER, C.; KAPPELLE, M. Nutrient fluxes in stemflow and throughfall in three successional stages of an upper montane rain forest in Costa Rica. Journal of Tropical Ecology, Cambridge, v. 19, p. 557-564, 2003.

INSTITUTO AGRONÔMICO DO PARANÁ. Sistema de monitoramento agroclimático do Paraná: estação de Guaraqueçaba. Disponível em: <http://200.201.27.14/Site/Sma/Estacoes_IAPAR/Estacoes_Parana.htm>. Acesso em: 07/03/2006.

JORDAN, C. F. The nutrient balance of an Amazonian rain forest. Ecology, Durham, v. 63, n. 3, p. 647654, 1982.

KELLMAN, M.; HUDSON, J.; SANMUGADAS, K. Temporal variability in atmospheric nutrient influx to a tropical ecosystem. Biotropica, Washington, DC, v. 14, n. 1, p. 1-9, 1982.

LEOPOLDO, P. R.; CONTE, M. L. Repartição de áhua em cobertura vegetal com características típicas de cerradão. In: SIMPÓSIO BRASILEIRO DE HIDROLOGIA E RECURSOS HÍDRICOS E SIMPÓSIOINTERNACIONAL DE RECURSOS HÍDRICOS EM REGIÕES METROPOLITANAS, 6., 1985, São Paulo. Anais... São Paulo: Associação Brasileira de Recursos Hídricos, 1985, p. 212-220.

LIKENS, G. E.; BORMANN, F. H.; PIERCE, R. S.; EATON, J. S.; JOHNSON, N. M. Biogeochemistry of a forested ecosystem. New York: Springer, 1977.

LIMA, W. P. Entrada de nutrientes pela chuva e pela lixiviação das copas das florestas homogêneas de pinheiros tropicais e em vegetação natural de cerradão. Acta Limnologica Brasiliensia, São Carlos, SP, v. 1, p. 503-525, 1986.

MAACK, R. Geografia física do estado do Paraná. Curitiba: Universidade Federal do Paraná, 1968.

MARQUES, R.; RANGER, J. Dinâmica hidrobiogeoquímica em um ecossistema florestal de clima temperado. In: FORUM DE GEO-BIO-HIDROLOGIA, ESTUDOS EM VERTENTES E 
MICROBACIAS HIDROGRAFICAS, 1., 1998, Curitiba. Anais... Curitiba: Universidade Federal do Paraná, 1998. p. 219-237.

MEGURO, M.; VINUEZA, G. N.; DELITTI, W. B. C. Ciclagem de nutrientes minerais na mata mesófila secundária - São Paulo. II - O papel da precipitação na importação de potássio e fósforo. Boletim de Botânica, São Paulo, v. 7, p. 61-67, 1979b.

MINEROPAR MINERAIS DO PARANÁ SA. Atlasgeo.pdf. Atlas geológico do estado do Paraná. Curitiba, 2001.

MOCOCHINSKI, A, Y.; WISNIEWSKI, C.; SCHEER, M. B.; PUTINI, F. A.; GATTI, G. A.; LORENZETTO, A.; CAVASSANI, A. T.. Solos e vegetação em uma área em processo de regeneração ambiental em Guaraqueçaba, PR. In: CONGRESSO BRASILEIRO DE CIÊNCIAS DO SOLO, 29., 2003, Ribeirão Preto, SP. Relação de trabalhos. Ribeirão Preto, 2003. 1 CD ROM.

OSTAPCZUK, P. Wet precipitation: rain and snow. In: STOEPPLER, M. (Ed.). Sampling and sample preparations: practical guide for analytical chemists. Berlin: Springer, 1997. p. 13-25.

SANTOS, V. D. Ciclagem de nutrientes minerais em mata tropical subcaducifolia nos planaltos do Paraná (Parque Estadual Vila Rica do Espírito Santo - Fênix/PR). 385 f. Tese (Doutorado em Ecologia e Recursos Naturais) - Departamento de Ciências Biológicas, Universidade de São Carlos, São Carlos, 1989.

SCHEER, M. B. Ciclagem de nutrientes em um trecho de Floresta Ombrófia Densa Aluvial em regeneração, Guaraqueçaba, PR. 155 f. (Dissertação de Mestrado em Engenharia Florestal) - Setor de Ciências Agrárias, Universidade Federal do Paraná, Curitiba, Curitiba, 2006.

SCHRUMPF, M.; ZACH, W.; AXMACHER, J. C.; LYARUU, H. V. M. Biogeochemistry of an afrotropical montane rain forest on Mt. Kilimanjaro, Tanzania. Journal of Tropical Ecology, Cambridge, v. 22 , p. $77-89,2006$.

SCHUBART, H. O. R.; FRANKEN, W.; LUIZÃO, F. J. Uma floresta sobre solos pobres. Ciência Hoje, São Paulo, v. 2, n. 10, 1984.

SILVA-FILHO, E. V.; OVALLE, A. R. C.; BROWN, I. F. Balanço de nutrientes em uma floresta tropical úmida, Parque Nacional da Tijuca, Rio de Janeiro. Acta Limnologica Brasiliensia, São Carlos, SP, v. 1, p. 479-499, 1986.

VELOSO, H. P.; RANGEL FILHO, A. L.; LIMA, J. C. A. Classificação da vegetação brasileira, adaptada a um sistema universal. Rio de Janeiro: IBGE, Departemento de Recursos Naturais e Estudos Ambientais, 1991.

VENEKLAAS, E. J. Nutrient fluxes in bulk precipitation and througfall in two montane tropical rain forests, Colombia. Journal of Ecology, Oxford, v. 78, p. 974-996, 1990.

VITOUSEK, P. M.; REINERS, W. A. Ecosystem succession and retention: a hypothesis. BioScience, Washington, DC, v. 25, n. 6, 1975.

VITOUSEK, P. M.; SANFORD JUNIOR., R. L. Nutrient cycling in moist tropical forest. Annual Review of Ecology and Systematics, Palo Alto, v. 17, p. 137-167, 1986.

WALTER, H. Vegetação e zonas climáticas. São Paulo: E. P. U., 1986. 